\title{
Histomorphological effects of sodium arsenite on uterus of rats
}

\author{
Amaidah Mir1*, Hammad Ahmed Butt' ${ }^{2}$, Maria Yasmeen', Anber Saleem³, \\ Ruqqia Shafi Minhas ${ }^{4}$, Sumaira Abbasi ${ }^{5}$
}

\author{
${ }^{1}$ Department of Anatomy, CPSP, Islamabad, Islamabad, Pakistan \\ ${ }^{2}$ Department of Pharmacology, CMH Kharian Medical College, Kharian, Punjab, Pakistan \\ ${ }^{3}$ Department of Anatomy, Islamabad Medical and Dental College, Islamabad, Pakistan \\ ${ }^{4}$ Department of Anatomy, Fazaia Medical College, Air University, Islamabad, Pakistan \\ ${ }^{5}$ Department of Anatomy, Federal Medical and Dental College, Islamabad, Pakistan
}

Received: 29 September 2020

Revised: 13 October 2020

Accepted: 14 October 2020

\section{*Correspondence:}

Dr. Amaidah Mir,

Email: amaidahmir@gmail.com

Copyright: (C) the author(s), publisher and licensee Medip Academy. This is an open-access article distributed under the terms of the Creative Commons Attribution Non-Commercial License, which permits unrestricted non-commercial use, distribution, and reproduction in any medium, provided the original work is properly cited.

\begin{abstract}
Background: Arsenic is highly toxic agent and a risk factor for disease and disability. Arsenic is present in drinking water of many developing and developed countries including Pakistan and due to rapid industrialization its quantity in soil and water is increasing day by day.

Methods: In an 18 month study in which we took two principal groups, labelled as control group A and experimental group B. The animals of experimental group B were administered $4 \mu \mathrm{g}$ of sodium arsenite dissolved in $10 \mathrm{ml}$ of distilled water by oral gavage daily for 14 days. The uterus was removed and processed for paraffin embedding and stained with hematoxylin and eosin ( $\mathrm{H}$ and $\mathrm{E}$ ). The histological parameters; uterine luminal diameter, height of uterine luminal epithelium, area occupied by epithelial component of uterine glands and the thickness of myometrium were measured and evaluated by civil AutoCAD 2013 software. The data was analyzed statistically with the statistical package for social sciences (SPSS).

Results: Histological results showed the degenerative effects. The luminal diameter of uterine horns was reduced in experimental animals. The height of uterine epithelium was reduced. Area occupied by epithelial component of uterine glands was reduced along the reduction in the thickness of myometrium.

Conclusions: The histological abnormalities observed in uterus showed that the degenerative effects may be due to oxidative stress produced by the exposure to sodium arsenite. As sodium arsenite produces the oxidative stress by the formation of free radicals and by the denaturation of proteins.
\end{abstract}

Keywords: Arsenic, Cervix, Free radicals, Oxidative stress, Uterus, Vagina

\section{INTRODUCTION}

Arsenic is highly toxic agent and a risk factor for disease and disability. Arsenic is present in drinking water of many developing and developed countries including Pakistan and due to rapid industrialization its quantity in soil and water is increasing day by day. ${ }^{1}$ The production of reactive oxygen species (ROS) i.e. hydrogen peroxide, superoxide anion radicals, lipid peroxidation, intracellular peroxide and hydroxyl free radicals are beholden to arsenic. Besides all this arsenic enhances the apoptosis by enzymatic and deoxyribonucleic acid (DNA) destruction with protein oxidation. $^{2}$

Arsenic is not only injurious to health but also has a lot of benefits i.e. it is a remedy for the parasitic infections in animals and for amebiasis and trypanosomiasis in humans. ${ }^{3,4}$ 
Arsenic is the main ingredient in manufacturing of pesticides and herbicides as monomethylarsonic acid. ${ }^{5}$ The acute arsenic poisoning is clinically categorized as: acute gastrointestinal and acute paralytic syndrome. According to the report of International agency for research on cancer (IARC) the increased exposure to arsenic and its aggregates are very carcinogenic. ${ }^{6}$ Arsenic is highly teratogenic and genotoxic agent. Arsenic also leads to edema formation, arrest in growth, spontaneous abortion, stillbirth, low birth weight and preterm birth. That's why such abnormalities are the primary cause of infant death. ${ }^{7}$

Following abnormalities occur in reproductive tract of males by exposure to arsenic; reduction of testicular and accessory sex organs weight, decline in number of epididymal sperm counts, variations in spermatogenesis, degeneration of germ cells at stage VII of the spematogenic cycle, decrease in diameter of seminiferous tubules and many gametogenic cells, i.e. resting spermatocyte, pachytene spermatocyte, and elongated spermatid. $^{8}$ The following hormonal levels are also decreased by exposure to arsenic; also the testosterone, gonadotrophins, luteinizing hormone (LH) and folliclestimulating hormone (FSH). On histology of testis arsenic has also that leads to the suppression of spermatogenesis and the maturation of sperms. ${ }^{8}$ Along all these arsenic has also deteriorating effects on the female reproductive tract. Arsenic reduces the size of oocytes in primary and primordial follicles, minimizes the width of zona pellucida (ZP) in antral and secondary follicles, reduces the volume and mean diameter of oocyte nuclei in all forms of follicles, decreases the volume of ovarian cortex, medulla and corpus luteum. Arsenic also decreases the serum LH and FSH levels with suppression of gonadotrophins secretions and ovarian steroidogenesis. ${ }^{9-13}$

The objective of the present work was to assess arsenic induced alterations in the uterus of female Sprague Dawley rats.

\section{METHODS}

This study was laboratory based experimental. It was done at the department of Anatomy, Islamabad regional centre, College of physicians and surgeons, Pakistan. Duration of study was 18 months from November 2017 to April 2019. Adult female Sprague-Dawley rats were purchased from the National Institute of Health (NIH), Islamabad. Their average age was 15-16 weeks and weight was 200-300 grams approximately. The female rats were kept in cages provided with hard wood chip bedding in an ordinary environment for 14 days in a room with 12-hour light-dark cycle, with $25 \pm 2{ }^{\circ} \mathrm{C}$ temperatures and $50-70 \%$ dampness and were fed with a standard pellet diet (purchased from the National Institute of Health Sciences, Islamabad) and water ad libitum. Six rats were housed per cage. On every third day the bedding was changed. The water proof ink marker was used to mark the rats. On every second day the markings were renewed.
The animals were randomly divided into two groups: group A was the control group in which thirty female rats were administered $10 \mathrm{ml}$ of pure distilled water by oral gavage daily for 14 days and group B was the experimental group. Thirty female rats were administered $4 \mu \mathrm{g}$ of sodium arsenite dissolved in $10 \mathrm{ml}$ of distilled water by oral gavage daily for 14 days. After 14 days of drug administration the rats from both groups were sacrificed. Each rat was euthanized by chloroform inhalation and when the rat showed no movements it was placed on a clean sheet of a paper on dissecting board for dissection. A midline incision was made on the abdominal skin by scalpel. Forceps were used to pull the muscle layers. During the whole process, the efforts were done to safeguard the genitourinary tract from any type of harm. Uterus was identified and removed. Tissue processing was done for routine histological study. The paraffin embedded sections of $5 \mu \mathrm{m}$ thickness after being stained with hematoxylin and eosin $(\mathrm{H}$ and $\mathrm{E})$ were observed under microscope from low to high power. The photographs of stained slide were taken by using the mobile camera through the Olympus binocular microscope at 10X lenses and shifted them to computer to apply the civil AutoCAD 2013 software. Uterine luminal diameter, height of uterine luminal epithelium, area occupied by epithelial component of uterine glands and thickness of myometrium were measured.

The data analysis was done statistically with the statistical package for social sciences (SPSS) computer software program, version 23. Student t-test was used to analyze the quantitative data. The quantitative parameters were all analyzed to find out any significant differences between the mean in the experimental and control groups. All the quantitative data was expressed as mean \pm standard deviation (SD). $\mathrm{P}$ value of $\leq 0.05$ was considered statistically significant.

\section{RESULTS}

The mean uterine luminal diameter \pm SD of control group $\mathrm{A}$ was $43941.389 \pm 7109.166 \mathrm{~mm}$. The mean uterine luminal diameter \pm SD of experimental group B was $23406.080 \pm 2269.874 \mathrm{~mm}$. This difference was statically significant with $\mathrm{p}$ value of 0.008 (Table 1).

The mean height of uterine luminal epithelium \pm SD of control group A was $11.601 \pm 0.565 \mathrm{~mm}$. The mean height of uterine luminal epithelium \pm SD of experimental group $B$ was $9.766 \pm 0.414 \mathrm{~mm}$. This difference was statically significant with $\mathrm{p}$ value of 0.011 (Table 1 ).

The mean area occupied by epithelial component of uterine glands \pm SD of control group A was $22109.133 \pm 1551.867$ $\mathrm{mm}^{2}$. The mean area occupied by epithelial component of uterine glands \pm SD of experimental group $B$ was $6357.8510 \pm 1178.699 \mathrm{~mm}^{2}$. This difference was statically significant with $\mathrm{p}$ value $<0.01$ (Table 1 ). 
Table 1: Comparison of control group A and experimental group B regarding quantitative parameters of uterus.

\begin{tabular}{|c|c|c|c|}
\hline \multirow{2}{*}{ Parameters } & A (control rats) & B (experimental rats) & \multirow{2}{*}{$P$ value } \\
\hline & $(\mathrm{n}=30)($ mean \pm SD $)$ & $(\mathrm{n}=30)($ mean \pm SD $)$ & \\
\hline Uterine luminal diameter (mm) & $43941.389 \pm 7109.166$ & $23406.080 \pm 2269.874$ & $0.008 *$ \\
\hline Height of uterine luminal epithelium (mm) & $11.601 \pm 0.565$ & $9.766 \pm 0.414$ & $0.011 *$ \\
\hline $\begin{array}{l}\text { Area occupied by epithelial component of } \\
\text { uterine glands }\left(\mathrm{mm}^{2}\right)\end{array}$ & $22109.133 \pm 1551.867$ & $6357.8510 \pm 1178.699$ & $<0.01 *$ \\
\hline Thickness of myometrium (mm) & $64.486 \pm 2.445$ & $57.405 \pm 2.487$ & $0.047 *$ \\
\hline
\end{tabular}

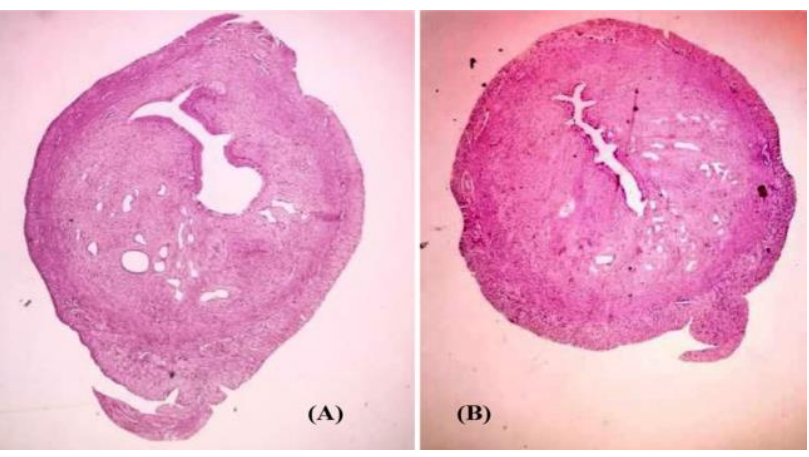

Figure 1: (A) cross section of uterine horn of control rat and (B) cross section of experimental rat.

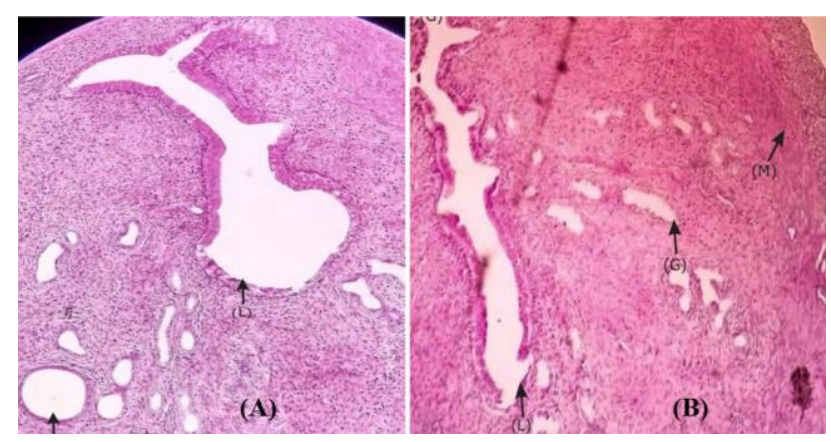

Figure 2: Comparison between endometrium of uterine horn of both control and experimental rat (A) the wide lumen $(\mathrm{L})$ and numerous glands $(G)$ in uterine endometrial stroma of control rat, and (B) the narrow uterine lumen $(L)$, glands $(G)$ in uterine endometrial stroma and the thin myometrium (M).
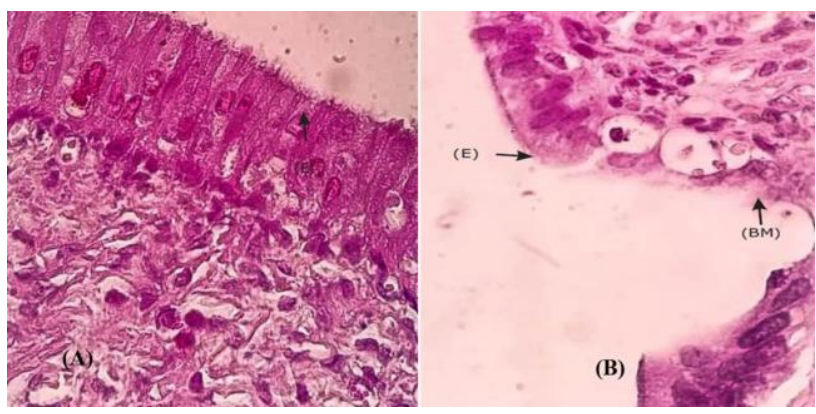

Figure 3: Comparison between the uterine luminal epithelium of control i.e. A and experimental i.e. B rat (A) the tall columnar (ciliated) epithelial cells (E) of uterine horn of control rat, and (B) low columnar epithelial cells $(E)$ of uterine horn of experimental rat.

\section{DISCUSSION}

The human beings are exposed to arsenic both by oral and inhalational routes and as a result of this arsenic is absorbed in the systems of body including digestive, respiratory and integumentary system. Due to its absorption, these systems undergo many diseases like hepatotoxicity, diabetes, cancers, cardiac and neurological disorders. In the present work, degenerative effects of sodium arsenite on the uterus are studied.

The mean uterine luminal diameter was significantly reduced in experimental group B as compared to the control group A (p value=0.008). This shows the toxic effects of arsenic on uterine endometrium. There are few possible mechanisms that support the reduction in uterine luminal diameter. The architecture of uterine endometrium remains normal by the production of estradiol (E2) in normal range. The E2 is produced by the ovaries. Arsenic decreases the E2 production from the ovaries and on endometrium arsenic has antiestrogenic activity. Another possible cause of decrease E2 level is that arsenic can easily form a bond with estrogen receptor (ER) and prevent the binding of E2 with alpha ER. So in the light of this mechanism it is clear that arsenic also acts on receptor level. So the decrease in E2 causes the disturbance of normal endometrial structure, e.g. the decrease uterine luminal diameter. ${ }^{15}$

The height of uterine luminal epithelium was reduced in experimental group B as compared to the control group A ( $p$ value $=0.011$ ). Normally the epithelium of uterus is simple columnar but in experimental uterus the uterine luminal epithelium was reduced to low columnar to simple cuboidal with rounded nuclei. The reduction in epithelial height shows the degenerative changes. According to many studies the degenerative changes in uterus are caused by reduction in serum estradiol levels whose normal range is very much important for the normal anatomy and physiology of female reproductive tract. The arsenic treatment decreases both estradiol and gonadotropins including FSH and LH. The reduction in $\mathrm{LH}$ and FSH will diminish the serum estradiol levels. According to another mechanism the gonadotropins to be remain in normal range depends on the normal secretion of glucocorticoids which are secreted from the adrenal cortex. ${ }^{16}$ Arsenic elevates the plasma glucocorticoids that will increase the production of corticosterone. When corticosterone is produced more than normal it will inhibit the gonadotroph cells sensitivity to 
gonadotropin-releasing hormone $(\mathrm{GnRH})$ that will decrease the gonadotropin. On the other side a stress signal pathway is activated by arsenic that will act on anterior pituitary to release adrenocorticotropic hormone (ACTH) in high quantity. Both elevated corticosterone and ACTH will decrease the production of estradiol..$^{9,17}$

In control group uterus the endometrial stroma was well occupied by endometrial glands but in experimental group the results were opposite as the area of endometrial stroma in experimental group was less occupied by endometrial glands ( $p$ value $<0.01$ ). The decrease in endometrial glands occupied area is due to diminish estradiol level. The estradiol regulates the functional differentiation and growth of uterus and also proliferates the endometrial glands. So if the levels of serum estradiol will reduce, they will degenerate the uterine morphology. ${ }^{18}$ According to a study progesterone is also very essential for the growth and maintenance of uterine glands. Arsenic not only diminishes the estradiol but also decreases the serum progesterone. So the decreased progesterone will lead to decrease proliferation of uterine glands. ${ }^{15,19}$

In control group uterus the myometrium was well thick but in experimental group the results showed the decrease in thickness of myometrium ( $p$ value=0.047). The myometrium of rat uterus has inner circular and outer longitudinal smooth muscles layers. The decrease thickness of myometrium is due to production of free radicals and reactive oxygen species by arsenic. These reactive oxygen species including $\mathrm{H}_{2} \mathrm{O}_{2}$, superoxide radicals and hydroxyl radicals. These all produce oxidative stress that is very harmful for the cellular components and lead to protein denaturation. Muscles are composed of proteins so any alteration in structure of proteins will be very harmful for the muscles. ${ }^{9,20}$

\section{Limitations}

Limitation of the study include being an animal based study, arsenic toxicity could be assessed in human patients. Financial expenditure limits our study and could be further elaborated with greater resources. Arsenic is a well-known toxin, whose handling required a certain degree of precaution and expertise.

\section{CONCLUSION}

Results of this study suggest that arsenic has degenerative effects on uterus of rat. Exposure to arsenic disrupts the normal histology of uterus. The changes in uterine luminal diameter were seen. The height of uterine epithelium, area occupied by epithelial component of uterine glands and thickness of myometrium were reduced.

Funding: No funding sources Conflict of interest: None declared

Ethical approval: The study was approved by the Institutional Ethics Committee

\section{REFERENCES}

1. Daud MK, Nafees M, Ali S, Rizwan M, Bajwa RA, Shakoor MB, et al. Drinking Water Quality Status and Contamination in Pakistan. Biomed Res Int. 2017;7908183.

2. Chowdhury S, Mazumder MA, Al-Attas O, Husain T. Heavy metals in drinking water: Occurrences, implications, and future needs in developing countries. Sci Total Environ. 2016;569-570:476-88.

3. Perry MR, Prajapati VK, Menten J, Raab A, Feldmann J, Chakraborti D, et al. Arsenic exposure and outcomes of antimonial treatment in visceral leishmaniasis patients in Bihar, India: a retrospective cohort study. PLoS Negl Trop Dis. 2015;9(3):e0003518.

4. Armienta MA, Rodríguez R, Cruz O. Arsenic Content in Hair of People Exposed to Natural Arsenic Polluted Groundwater at Zimapán, México. Bull Environ Contam Toxicol. 1997;59(4):583-9.

5. Punshon T, Jackson BP, Meharg AA, Warczack T, Scheckel K, Guerinot ML. Understanding arsenic dynamics in agronomic systems to predict and prevent uptake by crop plants. Sci Total Environ. 2017;5812:209-20.

6. Kosnett MJ. Arsenic. In: Brent J, Burkhart K, Dargan P, Hatten B, Megarbane B, Palmer R, et al., editors. Critical Care Toxicology: Diagnosis and Management of the Critically Poisoned Patient. Cham: Springer International Publishing. 2017;1639-67.

7. Rudnai T, Sándor J, Kádár M, Borsányi M, Béres J, Métneki $\mathrm{J}$, et al. Arsenic in drinking water and congenital heart anomalies in Hungary. Int $\mathrm{J}$ Hyg Environ Health. 2014;217(8):813-8.

8. Kim YJ, Kim JM. Arsenic Toxicity in Male Reproduction and Development. Dev Reprod. 2015;19(4):167-80.

9. Chatterjee A, Chatterji U. Arsenic abrogates the estrogen-signaling pathway in the rat uterus. Reprod Biol Endocrinol. 2010;8:80.

10. Dezfouli MGZ, Eissazadeh S, Zade SMAS. Histological and Histometrical Study of the Protective Role of $\alpha$-Tocopherol against Sodium Arsenite Toxicity in Rat Ovaries. Microsc Microanal. 2014;20(4):1167-79.

11. Sarkar M, Chaudhuri GR, Chattopadhyay A, Biswas NM. Effect of sodium arsenite on spermatogenesis, plasma gonadotrophins and testosterone in rats. Asian J Androl. 2003;5(1):27-31.

12. Mehta M, Hundal SS. Effect of sodium arsenite on reproductive organs of female Wistar rats. Arch Environ Occu Health. 2016;71(1):16-25.

13. Hong YS, Song KH, Chung JY. Health effects of chronic arsenic exposure. J Prev Med Public Health. 2014;47(5):245-52.

14. Patricio BP, Brantes S. Normal Menstrual Cycle. Intech Open. 2018.

15. Mondal S, Mukherjee S, Chaudhuri K, Kabir SN, Kumar Mukhopadhyay P. Prevention of arsenicmediated reproductive toxicity in adult female rats by 
high protein diet. Pharmaceutical Biol. 2013;51(11):1363-71.

16. Whirledge S, Cidlowski JA. Glucocorticoids, stress, and fertility. Minerva Endocrinol. 2010;35(2):109-25.

17. Jana K, Jana S, Samanta PK. Effects of chronic exposure to sodium arsenite on hypothalamopituitary-testicular activities in adult rats: possible an estrogenic mode of action. Reprod Biol Endocrinol. 2006;4:9.

18. Lim HJ, Wang H. Uterine disorders and pregnancy complications: insights from mouse models. J Clin Investig. 2010;120(4):1004-15.

19. Patel B, Elguero S, Thakore S, Dahoud W, Bedaiwy M, Mesiano S. Role of nuclear progesterone receptor isoforms in uterine pathophysiology. Hum Reprod Update. 2015;21(2):155-73.

20. Akram Z, Jalali S, Shami SA, Ahmad L, Batool S, Kalsoom O. Adverse effects of arsenic exposure on uterine function and structure in female rat. Exp Toxicol Pathol. 2010;62(4):451-9.

Cite this article as: Mir A, Butt HA, Yasmeen M, Saleem A, Minhas RS, Abbasi S. Histomorphological effects of sodium arsenite on uterus of rats. Int J Basic Clin Pharmacol 2020;9:1641-5. 